\title{
IDENTIFICAÇÃO E PERFIL DE RESISTÊNCIA BACTERIANA DE ISOLADOS DE HEMOCULTURAS PROVENIENTES DE UM HOSPITAL DE EMERGÊNCIA
}

\author{
D. G. ARAÚJO ${ }^{1}$, M. E. F. OLIVEIRA ${ }^{1}$ e S. R. de OLIVEIRA ${ }^{1}$ \\ 1 Grupo de Pesquisa em Patologia das Doenças Transmissíveis e Não Transmissíveis \\ (GPPATO), Centro Universitário Tabosa de Almeida - Asces-Unita \\ E-mail para contato: dany_melo_@hotmail.com
}

RESUMO - Este trabalho teve por objetivo identificar e determinar o pefil de resistência bacteriana de isolados de hemoculturas de um hospital de emergência. Foi realizado um estudo laboratorial descritivo transversal. As amostras sanguíneas foram semeadas em meio de cultura ágar Sangue de Carneiro e ágar

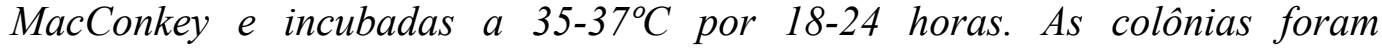
identificadas pela coloração de Gram e provas bioquímicas/enzimáticas. Os isolados foram submetidos ao antibiograma para determinação do grau de resistência aos principais antibióticos de uso hospitalar. Das 95 hemoculturas analisadas, $92 \%$ eram positivas, com predomínio do sexo masculino. O setor com maior número de isolados foi a UTI e o microrganismo mais prevalente foi o Staphylococcus saprophyticus. Quanto ao perfil de suscetibilidade, as cepas foram mais resistentes à Ceftriaxona, e mais sensíveis à Cefepime, seguido de Nitrofurantoína. A correta identificação laboratorial, bem como o monitoramento do perfil de resistência, podem auxiliar para um melhor direcionamento de medidas de controle da infecção, além de contribuir para a adoção da antibioticoterapia mais direcionada e eficaz.

Palavras-chave: Infecção nosocomial, Suscetibilidade, Antimicrobianos.

\begin{abstract}
This work aimed to identify and determine the profile of bacterial resistance of isolates of blood cultures from an emergency hospital. A crosssectional descriptive laboratory study was performed. Blood samples were seeded in Blood sheep agar and MacConkey agar and incubated at 35-37 ${ }^{\circ} \mathrm{C}$ for $18-24$ hours. The colonies were identified by Gram staining and biochemical / enzymatic assays. The isolates were submitted to the antibiogram to determine the degree of resistance to the main antibiotics for hospital use. Of the 95 blood cultures analyzed, 92\% were positive, with predominance male sex. The sector with the highest number of isolates was the ICU and the most prevalent microorganism was Staphylococcus saprophyticus. Regarding the susceptibility profile, the strains were more resistant to Ceftriaxone, and more sensitive to Cefepime, followed by Nitrofurantoin. The correct laboratory identification, as well as the monitoring of the resistance profile, can help to better target infection control measures, besides contributing to the adoption of the most targeted and effective antibiotic therapy.
\end{abstract}

Keywords: Nosocomial infection, Susceptibility, Antimicrobials. 


\section{INTRODUÇÃ̃O}

As infecções de corrente sanguínea têm sido consideradas um problema emergente, uma vez que sua incidência no ambiente hospitalar vem aumentando nas últimas décadas. Os principais agravos relacionados a esta infecção incluem as septicemias, que representam uma importante causa de mortalidade, prolongam o tempo de internação hospitalar e os custos com o paciente (GUILARDE et al., 2007; FREIRE et al., 2013).

Um dos exames laboratoriais mais importantes no diagnóstico de infecções na corrente sanguínea, muito comuns em hospitais de emergência, é a hemocultura, utilizada para isolar e identificar, laboratorialmente, microrganismos patogênicos no sangue de um paciente que se pressupõe ter uma infecção. Este exame apresenta um alto valor preditivo, uma vez que o resultado da mesma irá refletir diretamente na terapêutica a ser adotada pelos profissionais de saúde (OLIVEIRA et al., 2017).

A contaminação do ambiente hospitalar e a transmissão entre pacientes, muitas vezes mediada pelos profissionais de saúde e pelos equipamentos médicos, utilizados nos procedimentos aos quais os indivíduos são expostos, evidencia a importância da adoção de medidas preventivas de infecções e recursos humanos melhor capacitados (DETTORI et al., 2014).

O surgimento de resistência bacteriana é inevitável, porém o aumento na limitação do uso de antibióticos se deve, dentre outras razões, ao seu uso abusivo, realizado, muitas vezes, erroneamente por alguns profissionais da saúde, ocasionando uma seleção de bactérias mais resistentes e fazendo com que vários agentes antimicrobianos venham se tornando menos ativos, o que dificulta as opções de tratamento e aumenta o impacto clínico das infecções na corrente sanguínea. Dessa forma, uma política de uso de antimicrobianos melhor direcionada pode contribuir na redução das taxas de resistência e mortalidade causadas por tais infeções (MENEZES et al., 2004; MCGOWAN JR. et al., 2006; FERNANDES et al., 2011).

Considerando a importância do levantamento de dados epidemiológicos quanto à prevalência e o padrão suscetibilidade bacteriana visando à promoção de medidas de biossegurança mais eficazes bem como a adoção de medidas terapêuticas mais adequadas ao paciente, o objetivo do presente estudo é identificar e definir o perfil de resistência bacteriana de isolados de hemoculturas provenientes de um hospital de emergência.

\section{MATERIAIS E MÉTODOS}

Trata-se de um estudo laboratorial descritivo transversal, que analisou as hemoculturas obtidas do laboratório de patologia clínica de um hospital de emergência, na cidade de Caruaru, Agreste Pernambucano, no período de abril a outubro de 2015. A pesquisa foi iniciada após a aprovação pelo Comitê de Ética (Número do parecer: 1.256.386) do Centro universitário Tabosa de Almeida Asces-Unita. As amostras de hemoculturas foram devidamente encaminhadas, em condições ideais de transporte, do laboratório de patologia clínica do Hospital de emergência para o laboratório de microbiologia da Asces-Unita.

As amostras de hemocultura foram aspiradas e semeadas no meio de cultura ágar Sangue de Carneiro e ágar MacConkey, para visualização macroscópica das cepas. As placas foram incubadas em estufa a $35-37^{\circ} \mathrm{C}$ por 18 a 24 horas. As colônias foram inicialmente identificadas pela coloração de Gram, com base em seu desenvolvimento em meios de cultura seletivos e não seletivos e provas bioquímicas/enzimáticas (KONEMAN et al., 2008). 
Uma vez identificados, os isolados foram submetidos ao antibiograma pela técnica de difusão em disco de Bauer e Kirby (PIASKOWSKI et al. 2007), para análise do perfil de sensibilidade aos principais antibióticos de uso contra essas cepas e verificação da presença de possível resistência bacteriana. Para a realização do ensaio, inoculou-se a suspensão da bactéria em teste, ajustada ao padrão de 0,5 na escala de McFarland, sobre a superfície da placa de ágar Mueller-Hinton. Posteriormente, foram colocados discos de antimicrobianos e as placas foram incubadas em estufa bacteriológica a uma temperatura de $35-37^{\circ} \mathrm{C}$ por 18 a 24 horas, sendo todo o procedimento realizado de maneira estéril. $\mathrm{O}$ método foi realizado seguindo as recomendações do Clinical and Laboratory Standards Institute (CLSI 2015), assim como a escolha dos discos de antimicrobianos utilizados.

\section{RESULTADOS E DISCUSSÃO}

Do total de 95 hemoculturas analisadas, 92\% foram positivas, apresentando crescimento bacteriano. Entre as hemoculturas positivas, $66 \%$ foram referentes a indivíduos do sexo masculino e 34\% do sexo feminino.

Quanto aos setores do hospital, aquele que apresentou a maior presença de culturas positivas foi a Unidade de Terapia Intensiva (UTI) (62\%). Conforme a Figura 1, o índice de infecções na UTI se mostra elevado quando comparado aos demais setores hospitalares, o que pode ser explicado pelo fato de que os pacientes deste setor encontram-se normalmente comprometidos imunologicamente, devido à gravidade de suas patologias de base ou pelo fato de muitas vezes serem submetidos a procedimentos invasivos, o que os torna mais suscetíveis a infecções causadas por microrganismos oportunistas (HENES et al., 2013).

Figura - Incidência de hemoculturas positivas por setores de uma instituição hospitalar.

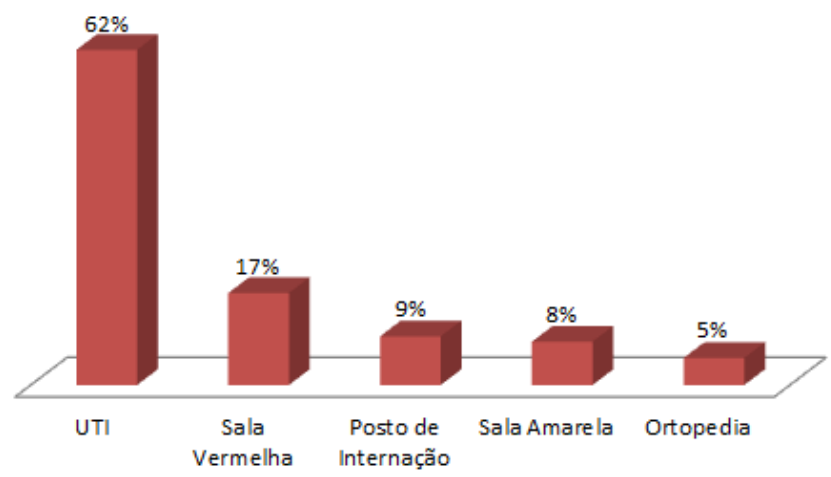

Entre as bactérias identificadas, o microrganismo mais prevalente foi o Staphylococcus saprophyticus (25\%), seguido de Staphylococcus aureus (22\%), Staphylococcus coagulase negativa (21\%) e Enterobactérias (13\%) (Figura 2). Estes dados entram em contraste com os trabalhos de Viana et al. (2011), Alves et al. (2012) e Silbert et al. (1997), cuja bactéria predominante em seus estudos foi o Staphylcoccus epidermidis, apontada por eles como o mais frequente Gram Positivo encontrado em hemoculturas, com incidência de $60 \%, 45,5 \% 91,1 \%$ respectivamente. 
Figura 2- Prevalência dos microrganismos isolados a partir de hemoculturas provenientes de um hospital de emergência.

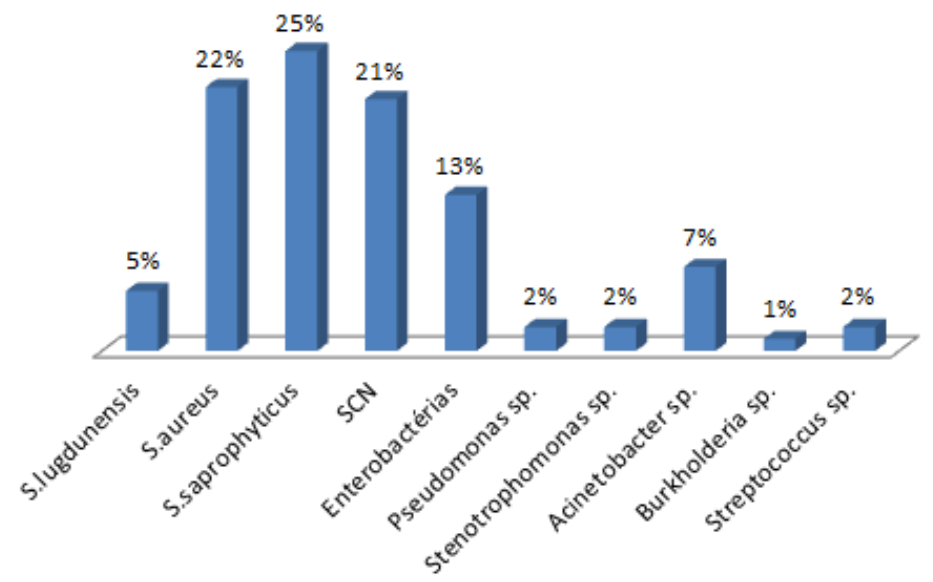

O achado de Staphylococcus lugdunensis neste estudo com 5\% foi um dado muito importante, tendo em vista que trabalhos envolvendo esta espécie são escassos. Apesar de menos frequente quando comparado aos demais do gênero Staphylococcus, o $S$. lugdunensis é um patógeno emergente com elevado potencial agressor (BARRETO E PICOLI, 2008).

Quanto ao perfil de resistência, as cepas testadas pelo antibiograma mostraram-se mais resistentes à Ceftriaxona (100\%), e mais sensíveis à Cefepime $(100 \%)$, seguido de Nitrofurantoína (82\%). O resultado do teste de suscetibilidade aos antimicrobianos mais utilizados frente aos isolados neste estudo pode ser encontrado na Tabela 1.

Tabela1 - Perfil de sensibilidade e resistência aos microrganismos isolados de hemoculturas.

\begin{tabular}{lcccc} 
& \multicolumn{2}{c}{ Sensibilidade } & \multicolumn{2}{c}{ Resistência } \\
\hline Antibióticos & $\begin{array}{c}\mathbf{N}^{\circ} \mathbf{d e} \\
\text { cepas }\end{array}$ & $\mathbf{\%}$ & $\begin{array}{c}\mathbf{N}^{\circ} \text { de } \\
\text { cepas }\end{array}$ & $\%$ \\
\hline Minociclina & 1 & 17 & 5 & 83 \\
Ciprofloxacina & 1 & 17 & 5 & 83 \\
Meropenem & 2 & 25 & 6 & 75 \\
Imipenem & 2 & 25 & 6 & 75 \\
Ceftriaxona & - & - & 6 & 100 \\
Ceftazidima & 3 & 27 & 8 & 73 \\
Amicacina & 2 & 25 & 6 & 75 \\
Gentamicina & 2 & 25 & 6 & 75 \\
Levofloxacina & 4 & 36 & 7 & 64 \\
Norfloxacina & 18 & 28 & 46 & 72 \\
Cefepime & 2 & 100 & - & - \\
Cloranfenicol & 41 & 37 & 24 & 63 \\
Cefoxitina & 13 & 21 & 49 & 79 \\
Eritromicina & 14 & 23 & 48 & 77 \\
Clindamicina & 18 & 28 & 46 & 72 \\
Nitrofurantoína & 51 & 82 & 11 & 18 \\
Tetraciclina & 28 & 45 & 34 & 55 \\
Linezolida & 44 & 71 & 18 & 29 \\
\hline
\end{tabular}


No presente estudo evidenciou-se a presença de cepas de MRSA (Methicillinresistant Staphylococcus aureus), que representam um importante patógeno nosocomial, relacionado a diversos fatores de risco como a internação em unidade de tratamento intensivo, prolongada hospitalização, doença de base grave, procedimentos invasivos e exposição prolongada ou repetida aos antimicrobianos (GELATTI et al., 2009). O uso de discos do antibiótico cefoxitina (CLSI, 2015) que atua como um marcador/ponto de corte para resistência às diversas cefalosporinas, indicando estirpes de MRSA, revelou um número elevado de cepas resistentes.

Neste estudo, o perfil de resistência em relação à cefoxitina, chegou a alcançar $79 \%$, onde obteve resultados semelhantes a outros trabalhos que utilizaram a oxacilina como opção, antibiótico este usado anteriormente para marcação de resistência frente a bactérias Gram positivas, como relatado por Silva et al. (2006) com 67\%, Guillarde et al. (2007) com 60,6\% e Alves et al. (2012) com 78,60\%. Tais resultados confirmam o aumento da resistência de bactérias Gram positivas do gênero Staphylococcus sp., limitando o uso deste grupo de antibióticos em UTIs.

Os carbapenêmicos são conhecidos como potentes agentes para o tratamento de infecções, principalmente as nosocomiais, entretanto, estudos já evidenciam redução da eficácia destes tratamentos (MARQUES et al., 2007; BIER et al., 2010). Este trabalho detectou significativa resistência aos carbapenêmicos no que se refere aos isolados que demonstraram $75 \%$ de resistência frente a ambos os carpanêmicos testados, imipenem e meropenem. Vale ressaltar que o emprego inadequado desta classe de fármacos pode exercer pressão seletiva sobre bactérias nosocomiais, gerando aumento de resistência bacteriana a eles devido à seleção de subpopulações menos sensíveis (PICOLI, 2008).

Levando em consideração os dados de prevalência e resistência supracitados, enfatiza-se a importância de que a comunidade científica esteja atenta a tais perfis, e assim possa intervir de acordo com a realidade local de cada unidade hospitalar.

\section{CONCLUSÃO}

O conhecimento sobre o perfil de suscetibilidade dos isolados em hemoculturas e sua correta identificação são fatores decisivos para o controle das infecções. A adoção de medidas preventivas e o fomento às medidas de biossegurança também são ferramentas essenciais para a diminuição de infecções nosocomiais causadas por microrganismos resistentes. Estudos como este, realizados periodicamente no ambiente hospitalar, podem auxiliar no controle de resistência e diminuição das taxas de mortalidade, tendo em vista que dados microbiológicos contribuem para um melhor direcionamento de medidas de controle da infecção e uso racional dos antibióticos em hospitais, auxiliando ainda na escolha terapêutica mais adequada para cada paciente.

\section{REFERÊNCIAS}

ALVES, L.N.S.; OLIVEIRA, C.R.; SILVA, L.A.P.; GERVÁSIO, S.M.D.; ALVES, S.R.; SGAVIOLI. G.M. Hemoculturas: estudo de prevalência dos microrganismos e o perfil de sensibilidade dos antibióticos utilizados em Unidade de Terapia Intensiva. $\boldsymbol{J}$. Health Sci Inst. v. 30, n. 1, p. 44-7, 2012.

BARRETO, M.F. E PICOLI, S.U. Staphylococcus em hospital de Porto Alegre (RS). Rev Bras Anal Clín. v.40(4): 285-287, 2008. 
BIER, K.E.S.; LUIZ, S.O.; SCHEFFER, M.C.; GALES, A.C.; PAGANINI, M.C.; NASCIMENTO, A.J.; CARIGNANO, E.; DALLA COSTA, L.M. Temporal evolution of carbapenem-resistant acinetobacter baumannii in Curitiba, Southern Brazil. Am J Infect control. v. 38 n.4, 2010.

CLINICAL AND LABORATORY STANDARDS INSTITUTE. Perfomance Standards for Antimicrobial Susceptibility Testing. Twenty-Second Informational Supplement M100-S22, 2015; 35(3).

DETTORI, M.; PIANA, A.; DERIU, M.G.; LO CURTO, P.; COSSU, A.; MUSUMECI, R.; COCUZZA, C.; ASTONE, V.; CONTU, M.A.; SOTGIU, G. Outbreak of multidrugresistant Acinetobacter baumannii in an intensive care unit. New Microbiol. 37(2):18591, 2014.

FERNANDES, A.P.; SILVA, C.J.; COSTA, C.; SCHREIBER, A.Z.; MELLO, F.A.; TEIXEIRA-LOYOLA, A.B.A. Incidência Bacteriana em Hemoculturas no Hospital das Clínicas Samuel Libânio de Pouso Alegre MG. Rev Elet Acervo Saúde. v.2, p.122-133, 2011.

FREIRE, I.L.S.; ARAÚJO, R.O.; VASCONCELOS, Q.L.D.A.Q.; MENEZES, L.C.C.; COSTA, I.K.F.; TORRES, G.V. Perfil microbiológico, de sensibilidade e resistência bacteriana das hemoculturas de unidade de terapia intensiva pediátrica. Ver Enferm UFSM. 3(3):429-239, 2013.

GELATTI, L.C.; SUKIENNIK, T.; BECKER, A.P.; INOUE, F.M.; CARMO, M.S.; CASTRUCCI, F.M.S.; PIGNATARI, A.C.C.; RIBEIRO, L.C.; BONAMIGO, R.R.; D'AZEVEDO, P.A. Sepse por Staphylococus aureus resistente à meticilina adquirida na comunidade no sul do Brasil. Rev Soc Bras Med Trop. 42(4):458-460, 2009.

GUILARDE, A.O.; TURCHI, M.D.; MARTELLI, C.M.T.; PRIMO, M.G.B.; BATISTA, L.J.A. Bacteremias em pacientes internados em hospital universitário. Rev. Assoc. Med. Bras. v.53, n.1, pp. 34-38. ISSN 0104-4230, 2007.

HENES, M.A.; SILVA, S.C.; FORNARI, J.V.; BARNABÉ, A.S.; FERRAZ, R.R.N. Incidência de infecção por Acinetobacter em uma unidade de tratamento especial de um hospital público do estado de São Paulo. Science in Health. 4(2):97-101, 2013.

KONEMAN, E.W.; ALLE, N S.D.; JANDA, W.M.; SCHRECKENBERGER, P.C.; WINN, W.C. Diagnóstico microbiológico: texto e atlas colorido. 6.ed. Rio de Janeiro: Guanabara Koogan, 2008.

MARQUES, P.B.; VIEIRA, A.B.R.; FARIAS, M.G. Perfil de suscetibilidade a antibióticos de amostras de Pseudômonas aeruginosa isoladas no centro de diagnóstico da Unimed Belém-Pará*. RBAC. v.39 (3):175-177, 2007.

MENEZES, E.A.; MACEDO, F.V.V.; CUNHA, F.A.; ANDRADE, M.S.S.; ROCHA, M.V.A.P. Perfil de infecção e resistência aos antimicrobianos de bacilos gram negativos não fermentadores isolados no laboratório de patologia clínica Dr.Edilson Gurgel, Santa Casa de Misericordia de Fortaleza-CE. RBAC. v.36(4): 209-212, 2004.

MCGOWAN, JR. J.E. Resistance in Nonfermentinhg Gram-Negative bactéria: Multidrug resistance to the maximum. Am J Med. v. 34 No. 5 Supplement 1, jun 2006. OLIVEIRA, M.E.F.; ARAÚJO, D.G.; OLIVEIRA, S.R. Resistance of non-fermenting Gram-negative bacilli isolated from blood cultures from an emergency hospital. J Bras Patol Med Lab. 53(2):87-91, 2017.

PIASKOWSKI, C.A.; YAMANAKA, E.H.U.; ROMANEL, M. Manual para antibiograma. Técnica de difusão por disco. Laborclin produtos para laboratórios ltda. Pinhais - PR. Maio, 2007.

PICOLI, S.U. Metalo-Beta-lactamase e Pseudômonas aeruginosa*. RBAC. v.40 (4): 237-277,2008. 
SILBERT, S.; ROSA, D.D.; MATTE, U.; GOLDIM, J.R.; BARCELLOS, S.H.; PROCIANOY, R.S. Staphylococcus sp. coagulase-negativa em hemoculturas de pacientes com menos de sessenta dias de idade: infecção versus contaminação. Jornal de Pediatria. v. 73, n.3, p.161-165, 1997.

SILVA, C.M.L.; SENA, K.X.F.R.; CHIAPPETA, A.A.; QUEIROZ, M.M.O.; VILLAR, M.C.M.; COUTINHO, H.M. Incidência Bacteriana em Hemoculturas. Rev. NewsLab. v. 20, n. 2, p. 132-144, 2006.

VIANA, A.P.P.; SOARES, R.S.; CASTRO, A.R.L.; KLUCZYNIK, C.E.N.; CATÃO, R.M.R. Incidência Bacteriana em hemoculturas de recém-nascidos e perfil de suscetibilidade frente aos antimicrobianos. Rev. Biofar. v.5, n.01. ISSN 1983-4209, 2011.

\section{AGRADECIMENTOS}

Ao Laboratório de Microbiologia do Hospital Regional do Agreste, pela disponibilidade das hemoculturas analisadas, e Centro Universitário Tabosa de Almeida ASCES/UNITA, pelo apoio financeiro e disponibilidade da infraestrutura do Laboratório Escola da Instituição. 